Pennerstorfer A \& Rutherford A, Measuring growth of the non-profit sector: The choice of indicator matters, Nonprofit and Voluntary Sector Quarterly (Volume 42, Issue 2), pp. 440-456. Copyright (C) The Authors 2018. Reprinted by permission of SAGE Publications.

\title{
Measuring growth of the non-profit sector: The choice of indicator matters
}

Astrid Pennerstorfer and Alasdair Rutherford

\section{Abstract}

Interestingly, although many authors consent that non-profit organizations and the non-profit sector have grown in many countries, there is little discussion of how to best measure this growth. Looking at the broad universe of non-profit organizations, there is no single measure that is relevant for the whole sector and captures changes adequately. This article gives an overview of commonly-used growth measures in the existing non-profit literature and discusses the informative value of the various measures. Using Austrian and Scottish time-series data we present an empirical example of how the growth story of the non-profit sector can change depending on the measures used. The correlations between measures such as the number of organizations, income/expenditures and assets are particularly small. We recommend that researchers measuring the growth of the non-profit sector should be clear about the properties of their selected measure, and where possible should present alternative measures in their analysis.

Keywords: growth, growth measures, non-profit sector, Austria, Scotland 
Pennerstorfer A \& Rutherford A, Measuring growth of the non-profit sector: The choice of indicator matters, Nonprofit and Voluntary Sector Quarterly (Forthcoming). Copyright (C The Authors 2018. Reprinted by permission of SAGE Publications.

\section{Introduction}

In many countries, non-profit organizations and the non-profit sector have grown in importance. Interestingly, although many authors consent that non-profit organizations and the non-profit sector grow and will continue to grow in many countries, there is little discussion about how to best measure this growth. In the for-profit sector, growth of employment, sales or value-added are the most common measures, each of them having advantages and disadvantages in its usage (Delmar, 2006). Some of these measures would not readily apply to the non-profit sector. Looking at the broad universe of non-profit organizations, there is no single measure that is relevant for the whole sector and captures changes or growth comprehensively.

Our article aims at giving an overview of the growth measures used in the existing non-profit literature and discusses the informative value of the various measures. We argue that each measure captures a different aspect of non-profit sector growth, and care should be used in selecting the appropriate measure(s) when describing the sector. Using Austrian and Scottish time-series data we present an empirical example of the sensitivity of sector growth to the measures used. These international examples allow us to show a range of measures across different contexts, illustrating the danger of drawing conclusions from one measure alone.

\section{Choosing between measures of the size and growth of the non-profit sector}

The non-profit sector incorporates idiosyncrasies that make measurement of growth difficult and that might explain the great variety of used measures. We conducted a 
comprehensive literature review of articles on non-profit growth to depict the variety of size indicators (see Table 1) and find that the number of organizations; the number of newly founded organizations; paid staff and volunteer work; membership volume; different measures of income and expenses; assets; or specific output measures are all used as indicators of size and growth. It is interesting to note that some of these measures are interrelated such as paid staff and expenses. Yet, the informative value of these measures differs, each with advantages and disadvantages.

Table 1: Overview of used growth indicators

- Table 1 here -

\section{Deciding which organizations to measure}

Although the debate about non-profit sector definition is an old one among non-profit scholars, the question of what to include in this definition is not yet settled (see Defourny, Grønbjerg, Meijs, Nyssens, \& Yamauchi, 2016; Salamon \& Sokolowski, 2016). In many countries, the non-profit sector is not a distinct sector in official statistics (United Nations, 2003, p. 1). This leads to relatively poor data, few reporting regulations for the organizations and much less knowledge of the sector compared to the for-profit sector. Consequently, researchers often do not have much choice about the indicators in use. In many countries substantial information deficits exist concerning the non-profit sector, and the datasets available will usually not have been created for the sake of scientific research.

For some countries, it is possible to use non-profit institutions serving households (NPISH) as a sector definition. This is part of the System of National Accounts (United Nations Statistics Division, 2009), which has the advantage that data are collected by internationally established standards and are available across many countries for a long 
period of time. However, this only captures one part of the non-profit sector and excludes non-profit organizations that are more business-like and rely more heavily on sales revenue to cover expenditure (Y. H. Kim \& Kim, 2016).

\section{Counting non-profit organizations}

The starting point in analyzing size variations is counting the number of non-profit organizations. This is the most commonly used indicator in this line of research (Corbin, 1999; Grønbjerg \& Paarlberg, 2001; J. Kim, 2000; M. Kim, 2015; Lecy \& Van Slyke, 2013; Lee, 2010; Liu, 2017; Luksetich, 2008; Marcuello, 1998; Matsunaga \& Yamauchi, 2004; Van Puyvelde \& Brown, 2016). Using the number of non-profit organizations is attractive, because it is a relatively easy to obtain and easy to understand measure. Depending on the data source, it may be a very comprehensive measure, taking into account all non-profit organizations irrespective of their activity field or degree of professionalization. However, it omits the aspect of organization size and thus market composition. Is it accurate to talk about stagnation in a case where only the existing non-profits grow (e.g. in employed staff, offered services, income or assets), but no new non-profits are being founded?

When counting organizations, it is useful to contrast active and registered non-profits. Casey (2016, p. 189), for example, reports on a decrease of 200,000 non-profits in the US between 2010 and 2013 that can be explained with a change in reporting regulations as most deregistered organizations were inactive. Conversely, not all active non-profits will necessarily have a reporting or registration requirement; often reporting thresholds by income will exclude smaller organizations. The difference between the population of organizations and those included in the data can be quite substantial. Furthermore, changing reporting thresholds within countries can make analysis over time problematic. Harrison and Laincz 
report that only about $38 \%$ of existing non-profit organizations in the US are included in the IRS data, with others falling below the threshold or failing to report (Harrison \& Laincz, 2008, p. 20). Within the UK, charities in England do not have to register if their income is below $£ 5,000$; while in Scotland all organizations must register in order to operate as a charity. Austrian administrative data on non-profit organizations only contain organizations that employ at least one paid person. According to estimations, only around $9 \%$ of all existing non-profit organizations have paid staff and are consequently required to report (Author 2013). The small organizations that are left out in many databases typically are self-help or voluntary grassroots initiatives that represent a specific part of the non-profit sector (Toepler, 2003).

Measures that focus on the flow, rather than the stock, of organizations can capture sector dynamics (Saxton \& Benson, 2005; Yu, 2016). While the inflow of new registrations may be well-recorded in administrative data, it can be more difficult to distinguish organizations in the outflow that cease to operate, miss filing deadlines, merge, or stop being required to register.

\section{Measuring financial characteristics}

Compared to for-profit organizations, non-profit organizations have very diverse funding sources ranging from earned income to donative income and membership fees. Consequently, we also find different income measures that could serve as a size indicator. Example income measures include donations per GDP (Pryor, 2012) and total revenue (Backus \& Clifford, 2013; Chikoto \& Neely, 2014; Clifford, 2016; Paarlberg \& Gen, 2009).

When using only one income source as an indicator, it is important to think about whether the income structure is comparable over time or space. In Austria, for example, the 
funding mode - and consequently the income structure - of many non-profit organizations has changed over the past 20 years. Many services delivered by non-profits were previously funded with lump-sum government subsidies. This changed as public service-contracting became more popular and now income from service contracting is recorded as earned income and not as a government grant (Author 2013). Measuring organizational growth with income from sales, in this case, overestimates growth as only the income structure changed without a corresponding increase in services. Conversely, relying only on a measure of total income does not capture the diversity of income sources. Organizations reliant on a small number of income sources rather than diversifying are likely to experience more volatile fluctuations in their growth (Carroll \& Stater, 2009; Mayer, Wang, Egginton, \& Flint, 2014).

Expenditure variables can be a proxy for output, especially useful when services are delivered below market prices or free of cost to service users, rendering income an incomplete measure. However, it is usual to only register activity that actually produces expenses. Services that are (co-)produced by (wage-free) volunteer work are not registered (fully) and thus expenditure underestimates the true size of an organization. In addition, improvements in efficiency will underestimate growth. Various output measures such as number of clients or housing units are often used when particular non-profit activity fields are the focus. It is, however, not possible to use this sort of indicator when measuring the whole non-profit sector, because there is no single meaningful output measure for all organizations.

Assets are also used as a proxy for size (Chikoto-Schultz \& Neely, 2016; Chikoto \& Neely, 2014; Harrison \& Laincz, 2008; Liu, 2017; Twombly, 2003). In a sector with fluctuations in income due to government policy and funding arrangements, assets might arguably provide a longer term measure of the size of the sector. Harrison and Laincz (2008) use this indicator and also discuss its problems. They mention that some non-profits have 
large endowments compared to the volume of provided services so that these organization have more weight in estimates of sector growth (Harrison \& Laincz, 2008, p. 20).

\section{Measuring non-profit personnel}

A distinctive feature of the non-profit sector is a workforce that consists both of paid employees and volunteers. Several studies use measures such as total employment (Bae \& Sohn, 2017; Ben-Ner \& Van Hoomissen, 1992) or volunteer and paid employment as a percentage of nonagricultural employment (Matsunaga, Yamauchi, \& Okuyama, 2010; Pryor, 2012; Salamon \& Anheier, 1998; Salamon, Sokolowski, \& Anheier, 2000). Paid employment can be measured by person-head count, full-time equivalents or employment relative to the population. These measures only capture non-profit organizations which employ paid staff, giving greater weight to industries such as social and health services that heavily rely on personnel input.

Volunteers are a very important and sometimes the only input factor in many nonprofits. Harrison and Laincz (2008, p. 20) cite that for the US neglecting volunteer work and using only paid employment would underestimate the economic weight of the non-profit sector by approximately 40 percent. Consequently, the unpaid workforce should ideally be included in a measure that concentrates on personnel. However, the lack of a market transaction in volunteering means that it often leaves little trace in the data. Usually, volunteers are not part of the organizations' accounting system (Sajardo \& Serra, 2011, p. 875) and there may be no official reporting requirements on volunteer volume, so that organizations without a professionalized volunteer management might not even be able to make a good estimation of their total volunteer volume (Mook, Handy, \& Quarter, 2007).

\section{Measuring non-profit sector composition}


Non-profit sector growth can result from two sources: the increase in the number of organizations (market entry) and/or the increase in organization size (organization growth). Both Tucker and Sommerfeld (2006) as well as Backus and Clifford (2013) consider the composition of the sector. The former analyze change in establishment sizes in US social service organizations; measuring size with employment (head) count. The latter have a similar endeavor, analyzing the composition of English and Welsh charities and differences in growth rates of organizations of different size (Backus \& Clifford, 2013). In their article, size is measured by the income of the charity (p. 764).

We have seen that the choice of measures could be determined by data availability, data quality, applicability to the (sub)sector of interest; and to the research question being answered. But importantly, choosing alternative measures may lead to different conclusions and so an appreciation of the sensitivity to choice of measure is critical in evaluating a research finding. We now go on to illustrate this point empirically using non-profit data from both Scotland and Austria.

\section{An empirical example: non-profit sector growth in Austria and Scotland}

For the empirical example, we use administrative data from two different sources: Austria and Scotland. We use these two countries as examples because of data availability, with different indicators available in each country. The aim is to illustrate the differences between growth indicators, rather than to make comparisons between the two countries.

\section{Data on the Austrian Non-profit Sector}

As in many other countries, quantitative information on the Austrian non-profit sector is scarce. No statistic covers the entire sector (Neumayr, Schneider, Meyer, \& Haider, 2007). 
The only administrative data that are available come from the Austrian pay slip and sales tax statistics provided by the Austrian Statistical office. They are available for the years 2003 to 2014 and incorporate only non-profit organizations that had at least one paid employee. As a size measure we use the number of organizations in each year, the income from sales, yearly payroll expenses and number of issued pay slips per year. All monetary values are deflated using the Austrian consumer price index with the year 2000 serving as the base year.

All Austrian employers have to report gross wages paid to employees in a given calendar year. Wages, on average, account for around 70 per cent of total expenses in the Austrian non-profit sector with paid employment (Author 2015). A pay slip is a sort of employment head count. It is issued yearly for each employee, but also each time the employment status of an employee changes. The number of pay slips therefore includes two dimensions - possible 'real' employment growth, but also employee turnover. Sales income can consist both of (privately) earned income and income from service-contracting with public authorities. Although not all organizations have sales revenues, it is the most important income category for Austrian non-profit organizations. On average, sales revenues account for around 72 per cent of total income for an Austrian non-profit organization that has paid employees (Author 2015). Almost 70 per cent of all sales income comes from public contractors, although there is a great variability between activity fields (Author 2015).

\section{Data on the Scottish Non-profit Sector}

Non-profit organizations in Scotland that wish to operate as charities must register with the Office of the Scottish Charity Regulator. Charitable status allows organizations to access a range of tax benefits in return for increased reporting requirements. Detailed organizational characteristics are collected at registration and through annual returns. 
Reliable information is available on charity finances, drawn from organizations' annual accounts, and broken down into standard sub-categories. However, unlike Austria, there is very little reliable information on the numbers of staff employed by organizations. Here we use a dataset of all active charities in Scotland between 2008 and 2014 that have submitted annual returns (Author 2018). All monetary values are deflated using the UK consumer price index with the base year as 2000 .

\section{Comparing the Growth Measures}

For the empirical example we present two different perspectives of growth aggregate sector growth and organizational growth within the sector. Starting with the sectoral perspective, Figure 1 depicts yearly non-profit sector growth rates for Austria and Scotland. Between the years 2003 and 2009, all Austrian measures register growth of the non-profit sector although growth rates differ. After 2009, some measures register a contraction of the sector in some years. The year 2010 stands out as a year with an actual decline of aggregated sales income, coinciding with the economic crisis and consequent welfare retrenchment measures, while growth in the total number of organizations went up in this year. Between 2004 and 2010, growth of sales income was smaller than growth of aggregated payroll expenses, but this reversed between 2011 and 2013.

A comparison of the aggregated values and the number of organizations contributing to these values enables us to make a statement about the composition of the sector. While growth in the number of organizations with income from sales has slowed since 2009 to an actual contraction after 2012, growth in aggregated sales income has risen between 2010 and 2013, meaning that the average sales income for an organization that receives sales income has increased. 
Looking at the growth rates of income and expenditure in Scotland, we find a similar pattern to Austria with positive growth rates prior to 2010 and negative growth rates until 2013. Income and expenditure growth are fairly stable, and mirror each other. For Scotland, we include two measures of assets: "Current Assets" are the liquid cash available to nonprofit organizations; while "Total Funds" is a measure of all assets, including property and long-term investments. Current asset growth is a much noisier measure; negative pre-2010 when the other measures were positive, and declining again in 2014 when income and expenditure growth are at their peak. Total Funds growth is smoother, but appears negatively correlated with income and expenditure. Current assets dropped dramatically in 2011, without a corresponding drop in Total Funds. While our initial enquiries established that this measure had not changed definition across the time period, a more in-depth examination of the historical reporting forms showed that the wording on other measures of assets had been altered slightly in that year. This appears to have led a number of large charities to reclassify their assets out of the Net Current Assets measure. These assets are still included in the Total Funds measure. This explains the apparent large drop in the current assets measure, and is an example which highlights the potential for measures to be strongly influenced by the way in which data is collected, even if the wording of the specific variable being analyzed remains constant.

Growth in the number of charities peaked in 2009, falling negative from 2013. The five measures clearly show different patterns, most pronounced in 2010 to 2012 when the number of organizations was growing, income and expenditure was stable or falling slightly, liquid assets were falling sharply, while total funds grew.

Figure 1: Yearly non-profit sector growth rates for Austria and Scotland 
- Figure 1 here -

Table 2 presents correlations between the growth rates of the various indicators. Values for Austria are reasonably correlated, with the highest correlation between growth of aggregated payroll expenses and growth of issued payslips. Aggregated sales income and the number of organizations exhibit the lowest correlation. Correlation values for Scotland make evident that the use of income and expenditure are quite similar, while there is virtually no correlation between income/expenditure and assets as well as the number of organizations in the non-profit sector.

Table 2: Correlations between growth indicators

\section{- $\quad$ Table 2 here -}

Next we examine the non-profit sector composition, following Backus and Clifford (2013). In their article, the authors ask if big charities are increasingly becoming more dominant, using data for English and Welsh charities for the years 1997 to 2008. They use income as a size variable in order to describe changes in organization size and thus market composition, and concentration. In a cross-sectional perspective, two ratios are calculated to examine changes in the concentration of income: the 100-charity concentration ratio and the top 1\% share (Backus \& Clifford, 2013, p. 764f.). In the cross-sectional perspective for England and Wales the authors find "relatively stable or slightly declining levels of concentration" (p. 766). We replicate this example for Austria and Scotland, using not only income as a variable but also expenses and assets, in order to analyze whether the answer to the question differs when choosing a different indicator.

Here we present the top $1 \%$ share, defined as the share of total income (expenditure, assets) captured by the largest 1\% of organizations each year (Backus \& Clifford, 2013, p. 
764). The ratio takes into account that the number of organizations changes each year. The ratio is calculated as:

$$
c_{k t}=\sum_{i=1}^{N} \delta_{i t} y_{i t} / \sum_{i=1}^{N} y_{i t}
$$

$c_{k t}$ represents the top $1 \%$ share $(\mathrm{k}=1)$ and $y_{i t}$ is the income (expenditure, assets) of organization $i=1, \ldots, N . \delta_{i t}$ is a dummy equaling 1 if the organization is among the top $1 \%$ of organizations in each year, and 0 otherwise.

Figure 2 shows the two concentration measures for Austria and Scotland. Turning to the income variables, we find an increase of income concentration between the years 2004 and 2009 in Austria when using the top $1 \%$ followed by a decline to levels that are very close to the year 2004. Using expenditure or employment instead of income we find an increase in concentration. Using expenditure or employment as size variables we could say that big organizations were becoming more dominant in the sample, while we would not have made this conclusion using the income variable.

Results for Scotland are even more striking. In Scotland we find a rising income concentration for the years 2008 to 2014 . However, asset concentration sharply declines across the period. Like Austria, we would also draw different conclusions about the dominance of big charities if we used assets instead of income as our measure.

Figure 2: Changes in sector composition

- $\quad$ Figure 2 here - 


\section{Discussion: can different measures tell different stories?}

In a world where non-profit activity in an economy and society is the exception rather than the rule, much energy has been devoted over the last 20 or more years in depicting the importance of this sector by presenting statistical analysis of organization numbers, employment or other activity measures. Yet, in contrast to the for-profit sector, there is no single measure that is fit to capture all non-profit activity in a complete way, given the many functions and activity fields of existing non-profit organizations.

Summing up the empirical illustration, we were able to show that growth rates of various indicators varied substantially within both Austria and Scotland. Correlations between the indicators were low; the results for Scotland reveal remarkably low correlation between assets, receipts and expenditures as well as the sheer number of organizations. The example examining the composition of the sector showed that we could draw the conclusion that market concentration increased or decreased over the years analyzed for both Austria's and Scotland's non-profit sectors depending on the choice of variable. One explanation for the low correlation of measures could be that indicators are more or less prone to aggregate shocks or cyclicity, or react with a varying time delay. Previous research in the for-profit sector has shown that firm growth chronologically follows a typical pattern and usually starts with employment growth, followed by sales growth, a growth of operating profits, and finally asset growth (Coad, Cowling, \& Siepel, 2017). Research on firms' reactions to economic shocks also found differences between employment and investment responses (Burger, Damijan, Kostevc, \& Rojec, 2017). Thus, low correlations between indicators may partly be explained by the indicators' different responses to broader economic trends. 
While the choice of the two countries may seem a bit arbitrary at first glance, the use of data for two countries enabled us to widen the choice of indicators. Our aim is not to compare the non-profit sectors in Scotland and Austria; rather, it is to illustrate methodological issues that would apply to measurement of the non-profit sector in any country. Scottish data are more complete, because Scottish organizations have more reporting regulations, although there is no reliable information about employment. The data include total income and total expenditure as well as assets, while Austrian data incorporate only the most important income and expenditure category, but have the advantage of including a person head count measure (payslips). Total income and expenses behave very similar, looking at the Scottish data. Using only the most important income and expenditure category in Austria, we find the two measures to sometimes diverge considerably. Measuring size using only one income or expenditure category can thus be especially problematic. Unfortunately, neither data sets include a measure of volunteering which would be another interesting and important indicator for non-profit activity. In addition, the used data sets cannot adequately demonstrate all data problems mentioned previously in section 2 , such as 'missing' non-profit organizations due to entry thresholds.

Rather than striving for the best measure that is universally applicable to the nonprofit sector as a whole, we discussed the advantages and disadvantages of a variety of choices. However, the bottom line may be that accurately quantifying large and diverse nonmarket activities directly is not possible. This does not mean that the existing measures are uninformative. On the contrary, each gives us an insight into a different dimension of nonprofit activity. The use of financial measures can make sense when non-profits are service providing/contracting organizations. However, in many other cases, significant 'non-market' elements make financial measures weaker. Focusing on measures that capture staff, 
volunteers and service-users could be a better alternative instead. Care must be taken to think about the adequacy of the used indicators in the given research setting and not to simply gloss over the simplifying assumptions implicit in selecting one measure over another when studying the non-profit sector. Where possible, alternative plausible measures should be reported and discussed, particularly where the choice of measure could lead to different conclusions. It is by being both transparent and precise that we will be best able to understand the dynamics of this increasingly important sector.

\section{Literature}

Author 2013

Author 2015

Author 2018

Backus, P., \& Clifford, D. (2013). Are big charities becoming more dominant?: cross-sectional and longitudinal perspectives. Journal of the Royal Statistical Society: Series A (Statistics in Society), 176(3), 761-776. doi:10.1111/j.1467-985X.2012.01057.x

Bae, K. B., \& Sohn, H. (2017). Factors Contributing to the Size of Nonprofit Sector: Tests of Government Failure, Interdependence, and Social Capital Theory. VOLUNTAS: International Journal of Voluntary and Nonprofit Organizations. doi:10.1007/s11266-017-9888-3

Bahmani, S., Galindo, M.-Á., \& Méndez, M. T. (2012). Non-profit organizations, entrepreneurship, social capital and economic growth. Small Business Economics, 38(3), 271-281. doi:10.1007/s11187-010-9274-7

Ben-Ner, A., \& Van Hoomissen, T. (1992). An empirical investigation of the joint determination of the size of the for-profit, nonprofit and government sectors. Annals of Public and Cooperative Economics, 63(3), 391-415. doi:10.1111/j.1467-8292.1992.tb02098.x

Burger, A., Damijan, J. P., Kostevc, Č., \& Rojec, M. (2017). Determinants of firm performance and growth during economic recession: The case of Central and Eastern European countries. Economic Systems, 41(4), 569-590. doi:https://doi.org/10.1016/i.ecosys.2017.05.003

Carroll, D. A., \& Stater, K. J. (2009). Revenue Diversification in Nonprofit Organizations: Does it Lead to Financial Stability? Journal of Public Administration Research and Theory, 19(4), 947-966.

Casey, J. (2016). Comparing nonprofit sectors around the world. What do we know and how do we know it? Journal of Nonprofit Education and Leadership, 6(3), 187-223. 
Chang, C. F., \& Tuckman, H. P. (1990). Do higher property tax rates increase the market share of nonprofit hospitals? National Tax Journal, 43(2), 175-187.

Chikoto-Schultz, G. L., \& Neely, D. G. (2016). Exploring the Nexus of Nonprofit Financial Stability and Financial Growth. VOLUNTAS: International Journal of Voluntary and Nonprofit Organizations, 27(6), 2561-2575. doi:10.1007/s11266-016-9786-0

Chikoto, G. L., \& Neely, D. G. (2014). Building Nonprofit Financial Capacity: The Impact of Revenue Concentration and Overhead Costs. Nonprofit and Voluntary Sector Quarterly, 43(3), 570588. doi:10.1177/0899764012474120

Clifford, D. (2016). Charitable organisations, the Great Recession and the Age of Austerity: Longitudinal Evidence for England and Wales. Journal of Social Policy, FirstView, 1-30. doi:doi:10.1017/S0047279416000325

Coad, A., Cowling, M., \& Siepel, J. (2017). Growth processes of high-growth firms as a fourdimensional chicken and egg. Industrial and Corporate Change, 26(4), 537-554. doi:10.1093/icc/dtw040

Corbin, J. J. (1999). A Study of Factors Influencing the Growth of Nonprofits in Social Services. Nonprofit and Voluntary Sector Quarterly, 28(3), 296-314.

David, G. (2010). Trends in Hospital Ownership Type and Capacity. Nonprofit and Voluntary Sector Quarterly, 39(2), 356-370. doi:http://journals.sagepub.com/doi/pdf/10.1177/0899764009333332

Defourny, J., Grønbjerg, K., Meijs, L., Nyssens, M., \& Yamauchi, N. (2016). Voluntas Symposium: Comments on Salamon and Sokolowski's Re-conceptualization of the Third Sector. VOLUNTAS: International Journal of Voluntary and Nonprofit Organizations, 27(4), 15461561. doi:10.1007/s11266-016-9743-y

Delmar, F. (2006). Measuring growth: methodological considerations and empirical results. In P. Davidsson, F. Delmar, \& J. Wiklund (Eds.), Entrepreneurship and the growth of firms (pp. 6284). Cheltenham, UK; Northampton, MA, USA: Edward Elgar.

Eimhjellen, I. S. (2014). Internet Communication: Does It Strengthen Local Voluntary Organizations? Nonprofit and Voluntary Sector Quarterly, 43(5), 890-909. doi:10.1177/0899764013487996

Grønbjerg, K. A., \& Paarlberg, L. (2001). Community Variations in the Size and Scope of the Nonprofit Sector: Theory and Preliminary Findings. Nonprofit and Voluntary Sector Quarterly, 30(4), 684-706. doi:10.1177/0899764001304004

Harrison, T. D., \& Laincz, C. A. (2008). Entry and Exit in the Nonprofit Sector. B.E. Journal of Economic Analysis and Policy: Contributions to Economic Analysis and Policy, 8(1). doi:http://www.bepress.com/bejeap/contributions/

Johnson, P. (2000). The size-age-growth relationship in not-for-profit tourist attractions: evidence from UK museums Tourism Economics, 6(3), 221-232.

Kim, J. (2000). The growth of the non-government sector in Korea and its relations with the state. Global Economic Review, 29(4), 20-42. doi:10.1080/12265080008449803 
Kim, M. (2015). Socioeconomic Diversity, Political Engagement, and the Density of Nonprofit Organizations in U.S. Counties. The American Review of Public Administration, 45(4), 402416. doi:doi:10.1177/0275074013504616

Kim, S. E., \& Kim, Y. H. (2015). Measuring the Growth of the Nonprofit Sector: A Longitudinal Analysis. Public Administration Review, 75(2), 242-251. doi:10.1111/puar.12306

Kim, Y. H., \& Kim, S. E. (2016). Testing an Economic Model of Nonprofit Growth: Analyzing the Behaviors and Decisions of Nonprofit Organizations, Private Donors, and Governments. VOLUNTAS: International Journal of Voluntary and Nonprofit Organizations, 27(6), 1-25. doi:10.1007/s11266-016-9709-0

Lecy, J. D., \& Van Slyke, D. M. (2013). Nonprofit Sector Growth and Density: Testing Theories of Government Support. Journal of Public Administration Research \& Theory, 23(1), 189-214. doi:10.1093/jopart/mus010

Lee, T. (2010). The Rise of International Nongovernmental Organizations: A Top-Down or Bottom-Up Explanation? VOLUNTAS: International Journal of Voluntary and Nonprofit Organizations, 21(3), 393-416. doi:10.1007/s11266-010-9137-5

Liu, G. (2017). Government Decentralization and the Size of the Nonprofit Sector. The American Review of Public Administration, O(0), 0275074016631643. doi:doi:10.1177/0275074016631643

Luksetich, W. (2008). Government Funding and Nonprofit Organizations. Nonprofit and Voluntary Sector Quarterly, 37(3), 434.

Marcuello, C. (1998). Determinants of the Non-profit Sector Size: An Empirical Analysis in Spain. Annals of Public and Cooperative Economics, 69(2), 175-192. doi:10.1111/1467-8292.00078

Matsunaga, Y., \& Yamauchi, N. (2004). Is the Government Failure Theory Still Relevant? A panel analysis using US state level data. Annals of Public and Cooperative Economics, 75(2), 227263. doi:10.1111/j.1467-8292.2004.00251.x

Matsunaga, Y., Yamauchi, N., \& Okuyama, N. (2010). What Determines the Size of the Nonprofit Sector?: A Cross-Country Analysis of the Government Failure Theory. VOLUNTAS: International Journal of Voluntary and Nonprofit Organizations, 21(2), 180-201. doi:10.1007/s11266-010-9125-9

Mayer, W. J., Wang, H.-c., Egginton, J. F., \& Flint, H. S. (2014). The Impact of Revenue Diversification on Expected Revenue and Volatility for Nonprofit Organizations. Nonprofit and Voluntary Sector Quarterly, 43(2), 374-392. doi:doi:10.1177/0899764012464696

Mook, L., Handy, F., \& Quarter, J. (2007). Reporting Volunteer Labour at the Organizational Level: A Study of Canadian Nonprofits. VOLUNTAS: International Journal of Voluntary and Nonprofit Organizations, 18(1), 55. doi:10.1007/s11266-007-9030-z

Neumayr, M., Schneider, U., Meyer, M., \& Haider, A. (2007). The Non-profit Sector in Austria - An economic, legal and political appraisal. Retrieved from Vienna: 
Nissan, E., Castaño, M.-s., \& Carrasco, I. (2012). Drivers of non-profit activity: a cross-country analysis. Small Business Economics, 38(3), 303-320. doi:http://dx.doi.org/10.1007/s11187$\underline{010-9276-5}$

Paarlberg, L. E., \& Gen, S. (2009). Exploring the Determinants of Nonprofit Coproduction of Public Service Delivery:The Case of k-12 Public Education. The American Review of Public Administration, 39(4), 391-408. doi:10.1177/0275074008320711

Pryor, F. L. (2012). Determinants of the size of the nonprofit sector. The European Journal of Comparative Economics, 9(3), 337-348.

Sajardo, A., \& Serra, I. (2011). The Economic Value of Volunteer Work: Methodological Analysis and Application to Spain. Nonprofit and Voluntary Sector Quarterly, 40(5), 873-895. doi:10.1177/0899764010371233

Salamon, L. M., \& Anheier, H. K. (1998). Social Origins of Civil Society: Explaining the Nonprofit Sector Cross-Nationally. VOLUNTAS: International Journal of Voluntary and Nonprofit Organizations, 9(3), 213-248. doi:10.1023/a:1022058200985

Salamon, L. M., \& Sokolowski, S. W. (2016). Beyond Nonprofits: Re-conceptualizing the Third Sector. VOLUNTAS: International Journal of Voluntary and Nonprofit Organizations, 27(4), 15151545. doi:10.1007/s11266-016-9726-z

Salamon, L. M., Sokolowski, S. W., \& Anheier, H. K. (2000). Social origins of civil society: An overview. Working papers of the Johns Hopkins Comparative Nonprofit Sector Project, 38.

Saxton, G. D., \& Benson, M. A. (2005). Social Capital and the Growth of the Nonprofit Sector. Social Science Quarterly, 86(1), 16-35.

Toepler, S. (2003). Grassroots Associations Versus Larger Nonprofits: New Evidence from a Community Case Study in Arts and Culture. Nonprofit and Voluntary Sector Quarterly, 32(2), 236-251. doi:10.1177/0899764003032002004

Tucker, D. J., \& Sommerfeld, D. H. (2006). The Larger They Get: The Changing Size Distributions of Private Human Service Organizations. Nonprofit and Voluntary Sector Quarterly, 35(2), 183203. doi:10.1177/0899764005283437

Twombly, E. C. (2003). What Factors Affect the Entry and Exit of Nonprofit Human Service Organizations in Metropolitan Areas? Nonprofit and Voluntary Sector Quarterly, 32(2), 211235. doi:10.1177/0899764003032002003

United Nations. (2003). Handbook on Non-Profit Institutions in the System of National Accounts. Retrieved from New York:

United Nations Statistics Division. (2009). The System of National Accounts. Retrieved from New York: http://unstats.un.org/unsd/nationalaccount/docs/SNA2008.pdf

Van Puyvelde, S., \& Brown, W. A. (2016). Determinants of Nonprofit Sector Density: A Stakeholder Approach. VOLUNTAS: International Journal of Voluntary and Nonprofit Organizations, 27(3), 1045-1063. doi:10.1007/s11266-015-9656-1 
Werker, E., \& Ahmed, F. Z. (2008). What Do Nongovernmental Organizations Do? Journal of Economic Perspectives, 22(2), 73-92. doi:doi: 10.1257/jep.22.2.73

Yu, Z. (2016). The Effects of Resources, Political Opportunities and Organisational Ecology on the Growth Trajectories of AIDS NGOs in China. VOLUNTAS: International Journal of Voluntary and Nonprofit Organizations, 27(5), 2252-2273. doi:10.1007/s11266-016-9686-3 